\title{
FRONTAL SINUS OBLITERATION UTILIZING AUTOGENOUS ABDOMINAL FAT GRAFT
}

\author{
Abla Eledeissi* and Mamdouh Sayed Ahmed ${ }^{* *}$
}

\begin{abstract}
Introduction \& Purpose: Frontal sinus fractures pose an interesting and challenging problem, as optimal treatment strategies for their management remain controversial. These fractures are peculiar in that a wrong treatment encompasses not only functional or aesthetical problems but also more dangerous complications. Various techniques have been advocated to repair or remove the frontal sinus that depend on the mechanism and extent of the injury and the status of the nasofrontal duct (NFD). Management options include: observation, open reduction and fixation of anterior table, sinus obliteration (with a wide range of materials); and, in more complex situations, sinus cranialization, and endoscopy (not in complex cases but in simple minimally displaced fractures). The purpose of this study was to assess clinically and radiographically frontal sinus obliteration technique utilizing autogenous abdominal fat graft.
\end{abstract}

Patients \& Methods: This study was carried out on 10 patients suffering unilateral and/or bilateral anterior table fracture of their frontal sinuses approximating the nasofrontal duct and having intact posterior tables indicated for sinus obliteration, selected from Cranio-Maxillofacial Surgeryl Department, Nasser Institute Hospital. All Patients were treated under general anesthesia and the sinus was approached either through a bicoronal approach or the existing lacerations. All sinuses were obliterated using autogenous abdominal fat graft and the anterior table was reduced and fixed with rigid internal fixation and the associated fractures were managed as required. All patients were clinically evaluated for any signs or symptoms of intracranial infections (brain abscess or meningitis), wound dehiscence, Sinus affections (sinusitis-mucocele- pyomucocele) or aesthetic deformity. Computerized tomography (CT) radiographic evaluations were carried out at immediate and 12 months post operatively to evaluate any uneventful healing of the graft detected by the amount of sinus expansion, thinning or bone erosion and bone occupying lesions or infection.

Results: In the current study, motor vehicle accidents were the most common cause and $90 \%$ of the included subjects were males with a mean age of 35 years (21-53). In $80 \%$ of the studied sample, the frontal sinus fracture was associated with other maxillofacial fractures, other $20 \%$ was isolated sinus Fracture. Clinical follow-up showed no neurologic impairment, no cerebrospinal fluid leak, no postoperative infection or wound dehiscence except only one case (10\%). Radiographic follow-up revealed that the abdominal fat grafts underwent uneventful healing and no abnormality was detected in the sinus cavity throughout the whole postoperative period.

* Assistant Lecturer of Oral and Maxillofacial Surgery, Misr International University.

** Professor of Oral and Maxillofacial Surgery, Oral and Maxillofacial Surgery Department, Faculty of Oral and Dental Medicine, Cairo University. 
Conclusion: Frontal sinus obliteration using autogenous abdominal fat appears to be successful and useful for patients with anterior table fractures.

KEYWORDS: Frontal sinus fractures, Frontal sinus obliteration, abdominal fat graft.

\section{INTRODUCTION}

Frontal sinus fractures are relatively uncommon and pose an interesting and challenging problem. Incidence of frontal sinus fracture varies from $2 \%$ to $15 \%$ of all facial fractures ${ }^{(1,2)}$.

Most of the injuries are a result of high-velocity impacts, in particular, those involving automobile and motorcycle accidents. Injuring forces capable of disrupting and displacing the anterior table frequently involve the posterior table and the elements of the floor of the anterior cranial fossa, resulting in damage to intracranial structures in 33$70 \%$ of patients with frontal sinus fractures ${ }^{(3,4)}$.

The importance of management of frontal sinus fracture relates to its proximity to these critical structures. Fractures involving the frontal sinus may result in both short and long-term complications and sequelae related to the sinus, intracranial, orbital and nasal structures. Complications that have been reported, included meningitis, brain abscess, chronic sinusitis, and mucocele formation ${ }^{(5,6)}$.

The surgical goals in the treatment of frontal sinus injuries are to provide an esthetic outcome, restore function, and prevent complications. There is no universal agreement on how to achieve these goals, and indeed no consensus on when surgical intervention is indicated. Various techniques have been advocated to repair or remove the frontal sinus that largely depend on the mechanism and extent of the injury and the status of the nasofrontal duct (NFD). These operations include open reduction and internal fixation of the anterior table, obliteration, and cranialization ${ }^{\cdot(7,8)}$

Most surgeons agree that nondisplaced fractures of the anterior table with no evidence of NFD obstruction should be treated non-operatively. Management of patients with more complex injuries, however, remains controversial ${ }^{(9-11)}$.

To date, there have been few long-term studies of frontal sinus injuries and therefore choice of surgical treatment has been based more on anecdotal information and personal experience. A number of well accepted management algorithms have been proposed, but few have been validated in recent years. The creation of a "safe sinus" is a worthy goal nonetheless ${ }^{(8)}$.

One of the most commonly accepted management algorithms is that proposed by Bell and colleagues. (12) Two factors were important determinants in this algorithm namely the injury of the nasofrontal duct and comminution of the posterior table. ${ }^{(12)}$

Another treatment algorithm was proposed by Rohrich and Hollier in 1992. ${ }^{(11)}$ Injury of the nasofrontal duct and CSF leak were the key determinants in deciding the treatment plan in this algorithm. Rohrich and Hollier suggested that patients with frontal sinus fractures were treated in four different ways based on the type of injury: (1) no surgical intervention, when the fractures were non comminuted, nondisplaced, not accompanied by cerebrospinal fluid leaks, and not involving the nasofrontal duct; (2) open reduction and internal fixation of the anterior table with sinus preservation in patients with fractures not involving the nasofrontal duct; (3) open reduction and internal fixation of the anterior table with sinus obliteration in fractures involving the nasofrontal duct; and (4) cranialization, when the posterior table had to be removed during exploration of intracranial lesions ${ }^{(5)}$. 
In all algorithms, it was always agreed that compromise of the nasofrontal duct mandates sinus obliteration. Obliteration involves the elimination of the frontal sinus cavity while maintaining the anterior and posterior tables. The most important principles for successful obliteration include the meticulous removal of all visible mucosa, the removal of the inner cortex of the sinus wall, and the permanent occlusion of the frontonasal duct. The frontal sinus is treated as an isolated cavity, precluding any potential mucosal regrowth from the nasal epithelium ${ }^{(13)}$.

There have been several reports on various materials used to obliterate the frontal sinus. These include gelfoam, bone chips, adipose tissue, temporalis fascia, pericranium, bio-glass, polytetrafluoroethylene-carbon fiber, calcium sulfate, methylmethacrylate, oxidized cellulose, hydroxyapatite, and lyophilized cartilage. This myriad of autogenous and alloplastic materials has been used with varying degrees of success for obliteration of the frontal sinus and the nasofrontal ducts (NFD) ${ }^{(14,15)}$.

The volume of material needed is highly variable, averaging approximately 35 to $40 \mathrm{~cm}^{3}$ but with as much as $200 \mathrm{~cm}^{3}$ needed in some cases. Although each material has its own advantages and disadvantages, autogenous grafts are preferable to allogeneic materials because of their extensive clinical history and favorable long-term treatment results ${ }^{(13)}$.

Bergara and Itoiz ${ }^{(16)}$ showed that viable implanted adipose tissue along with the removal of mucosal lining from the sinus consistently prevented regrowth of the mucoperiosteum and therefore advocated use of autogenous fat for obliteration purposes. Since the recommendation of Bergara, fat has been widely used and has been accepted as a reliable obliterating material for the frontal sinus. The purpose of this study was to evaluate the abdominal fat graft and assess its complication rates when used as an obliteration material in the frontal sinus obliteration technique.

\section{MATERIALS AND METHODS}

The present study was conducted on 10 adult patients admitted to the Cranio-Maxillofacial Surgery Department, Nasser Institute Hospital. The criteria for patient selection for this study included frontal sinus fracture involving the anterior table and associated injury to the nasofrontal duct with no or little involvement of the posterior table which all were indicated for duct obstruction and frontal sinus obliteration.

\section{Inclusion criteria:}

- Patients suffering from comminuted anterior table fracture of their frontal sinuses.

- Patients suffering from displaced fractures of the anterior table; equal or more than thickness of anterior table of frontal sinus as it appear in the axial CT cuts (Fig.1a, b).

- Patients suffering from anterior table fracture with nondisplaced posterior table fracture.

- Patients suffering from fractures of medial third of frontal sinus.

- Patients suffering from fractures involving the orbital roof.

\section{Surgical technique:}

All patients were evaluated according to the general rules of emergency care including airway management and control of bleeding if present. Frontal sinus fractures were assessed as part of general head injury evaluation. Neurological and ophthalmological consultations were performed for other associated injuries. Computed tomography (CT) was done for all patients with coronal, axial, sagittal and 3-dimentional reconstructions preoperatively and immediate postoperatively. Bases on CT, the degree of injury to the anterior and posterior tables as well as the nasofrontal duct was determined. 


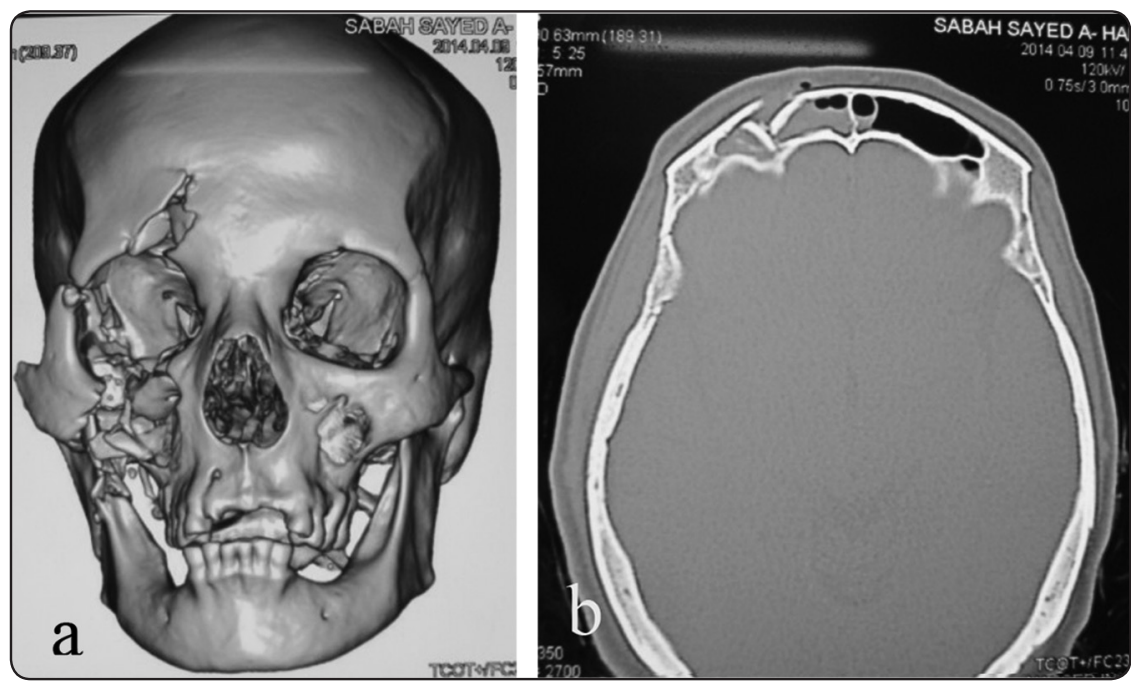

Fig. (1a): Preoperative 3D CT showing right side anterior table fracture of the frontal sinus with comminuted right $\mathrm{ZMC}$ and orbital floor Fracture.

Fig. (1b): An axial cut CT showing the unilateral displaced anterior table fracture of the right frontal sinus.

All surgical procedures were performed under general anesthesia. The fractured frontal sinus was exposed via a bi-coronal incision or through an existing laceration (Fig. 2). The fractured anterior table fragments were removed and debrided of any mucosal linings with rotary drill under copious irrigation and after that stored in a normal saline. The frontal sinus membrane was also removed with rotary egg shell bur and attention was given to the recesses of the frontal sinus and sometimes partial removal of a layer of bone throughout the sinus was required to ensure no remnants of mucosal lining

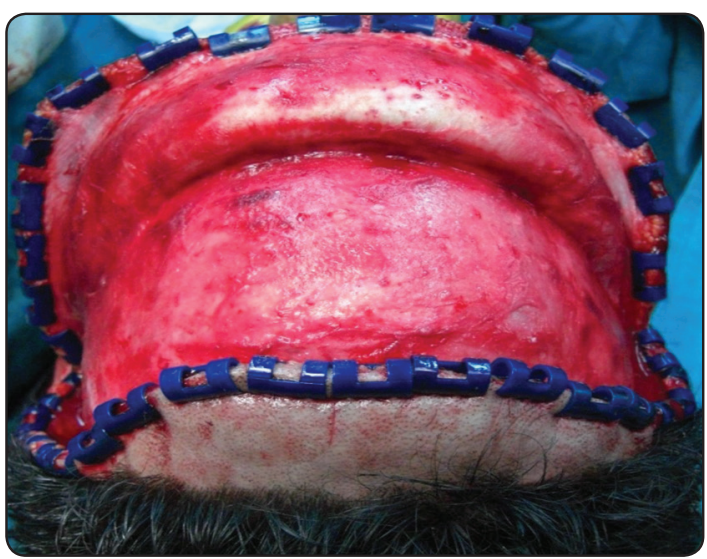

Fig. 2: Coronal incision and dissection in the subgaleal plane. were left $(3 a, b)$.

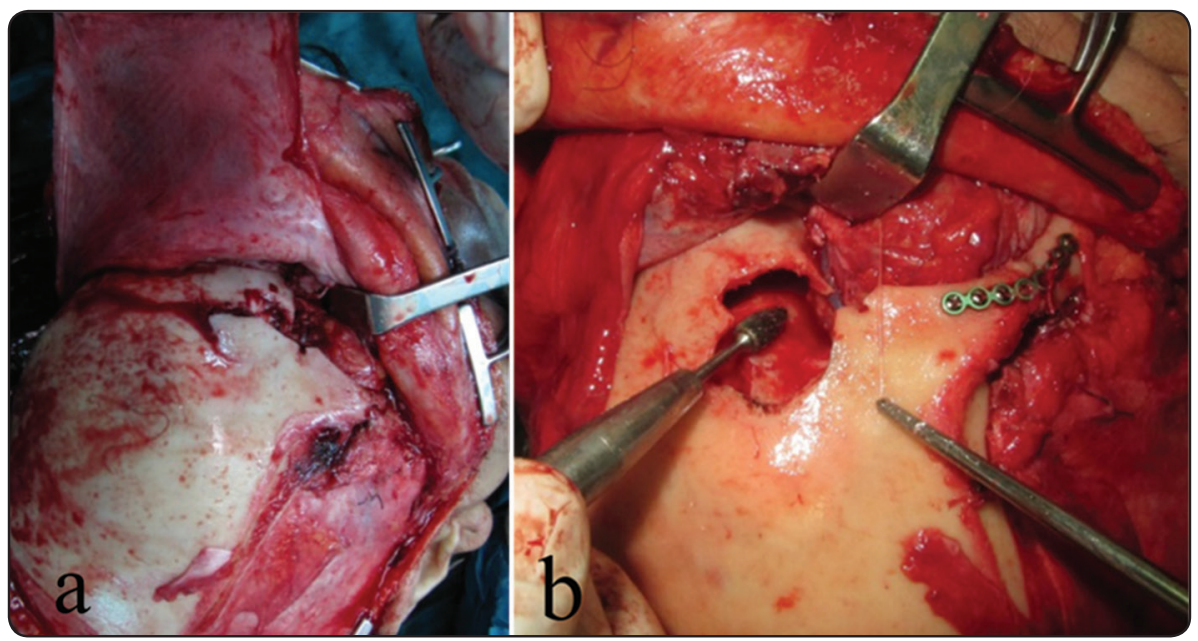

Fig. (3a): Elevation of a bicoronal flap to expose anterior table fracture of the frontal sinus.

Fig. (3b): After anterior table removal, the sinus membrane and the nasofrontal duct epithelium was removed with rotary bur. 
Obstruction of the nasofrontal duct was performed for separation of the frontal sinus from the nasal cavity and also to avoid regrowth of mucosa from the ethmoid into the frontal sinus. The NFDs were obstructed using either pericranium, temporalis muscle, or fascia together with bone chips.

Abdominal fat graft was harvested through a 4 $\mathrm{cm}$ transverse, midline or side incision below the umbilicus. Care was taken to limit the dissection superficial to the abdominal muscular fascia (Fig. 4a). Appropriate amount of fat was harvested and the wound closed by subcutaneous and skin sutures. The sinus was then obliterated with the harvested fat (Fig.4b).Finally, the anterior table was reconstructed using a 1.0 or $1.5 \mathrm{~mm}$ plating system (Fig 5a). In Some Cases due to extensive comminution of the anterior table, titanium mesh was used to reconstruct missed bone and guarantee proper contour of the frontal bone to avoid any aesthetic deformity (Fig. 5b). Associated nasoethmoid and orbital fractures was reduced and fixed at this point by fixation onto stable bone in the frontal region. The bi-coronal incision or the forehead laceration was closed in layers and a pressure dressing was placed for 48 hours. A Jackson Pratt drain was placed when the bi-coronal incision was used and it was removed when the drainage was less than $25 \mathrm{ml}$ per 24 hours. Patients were maintained on appropriate antibiotics (5 days), nasal decongestants, and analgesics postoperatively.

\section{Postoperative Evaluation:}

In the present study postoperative clinical evaluation was carried to evaluate the following: intracranial Infections (brain abscess or meningitis), wound Infection (soft tissue), osteomyelitis, wound dehiscence, aesthetic deformity and sinus affections (sinusitis-mucocele-pyomucocele). Radiographic evaluation of all patients was done using computerized tomography (CT) scanning immediately and at 12 months post operatively. Cases were considered radiographically successful when sinuses were free of pathology and the anterior table was correctly reduced.
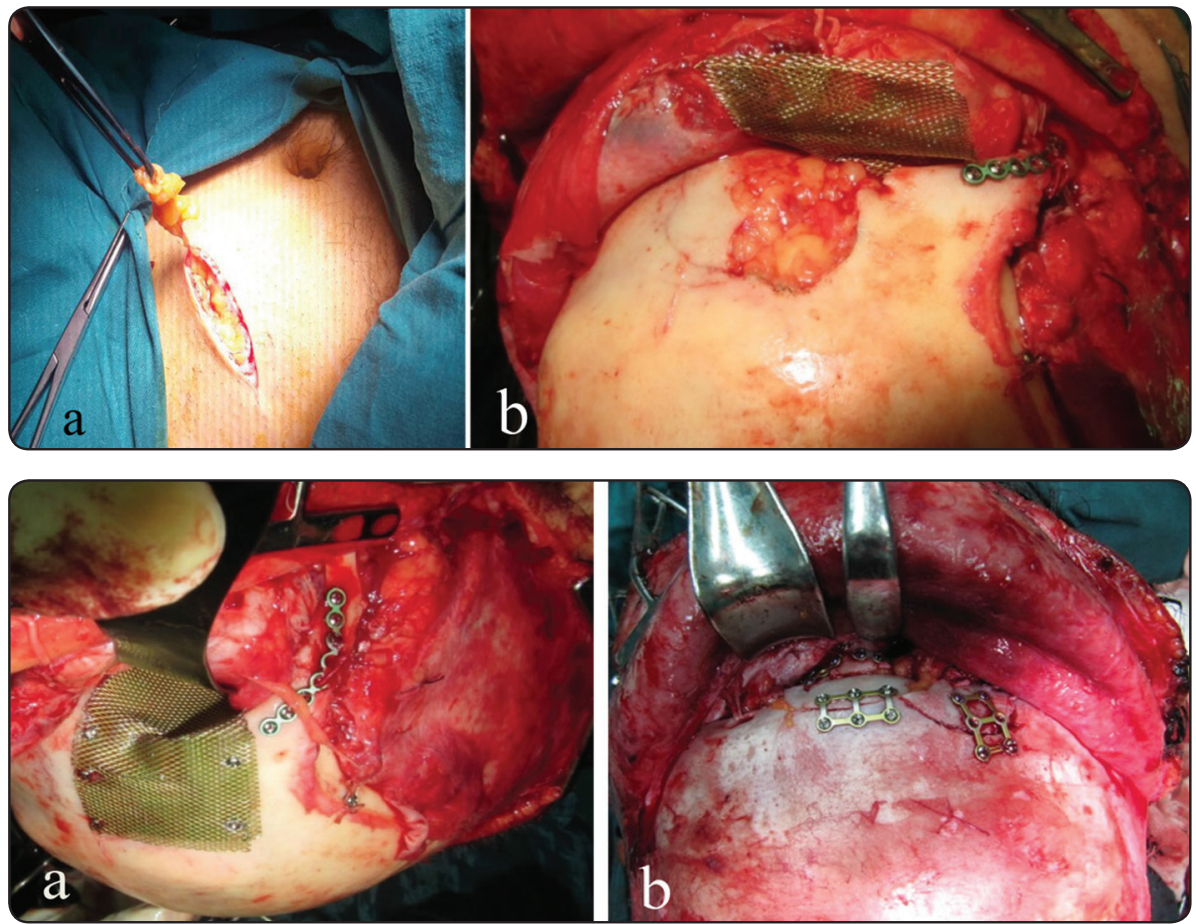

Fig. (4a) Harvesting of the abdominal fat graft.

Fig. (4b) Frontal sinus obliteration with abdominal fat graft.

Fig. (5a) Reconstructing the anterior table with titanium mesh case 2 .

Fig. (5b) Reduction of anterior table Fragments and rigid fixation with plates and screws case 7 . 


\section{RESULTS}

This study included 10 adult patients ( 9 male and 1 female) with the mean age of 35 years (21-53). The mechanism of injury was road traffic accident in 8 patients, and two patient's injury were a result from fall from height.

In the current study, isolated anterior table fracture of the sinus were found in half of the patients (5 patients) while combined anterior and posterior fractures were found in the other half (5 patients). Nine frontal sinuses were approached through a coronal incision and only one sinus approached through an existing laceration.

In this study, eight of ten patients presented with associated maxillofacial fractures. The most frequently associated facial fracture was orbital fractures which was present in 8 patients. Other associated facial fractures included zygomatic fractures in 5 patients, naso-orbitoethmoid fractures in 3 patients, Le Fort I fractures in 2 patients and mandible fractures also in 2 patients.

Clinical follow-up showed no signs of infection or wound dehiscence in 9 cases while one case was infected 1 week post-operatively with edema and pus oozing through the wound. In this case, the sinus was approached through an existing laceration. The treatment consisted of incision and drainage, irrigation and antibiotic treatment with an uneventful course afterwards. No neurologic impairment, CSF leak, or mucoceles were observed during the 1 year follow-up period in any of the ten cases. Radiographically, all the abdominal fat grafts underwent uneventful healing and no abnormality was detected in the sinus cavity throughout the whole postoperative period (Fig. 6a,b). One year follow-up showed no evidence of complications, bone occupying lesions or infection (Fig. 7).

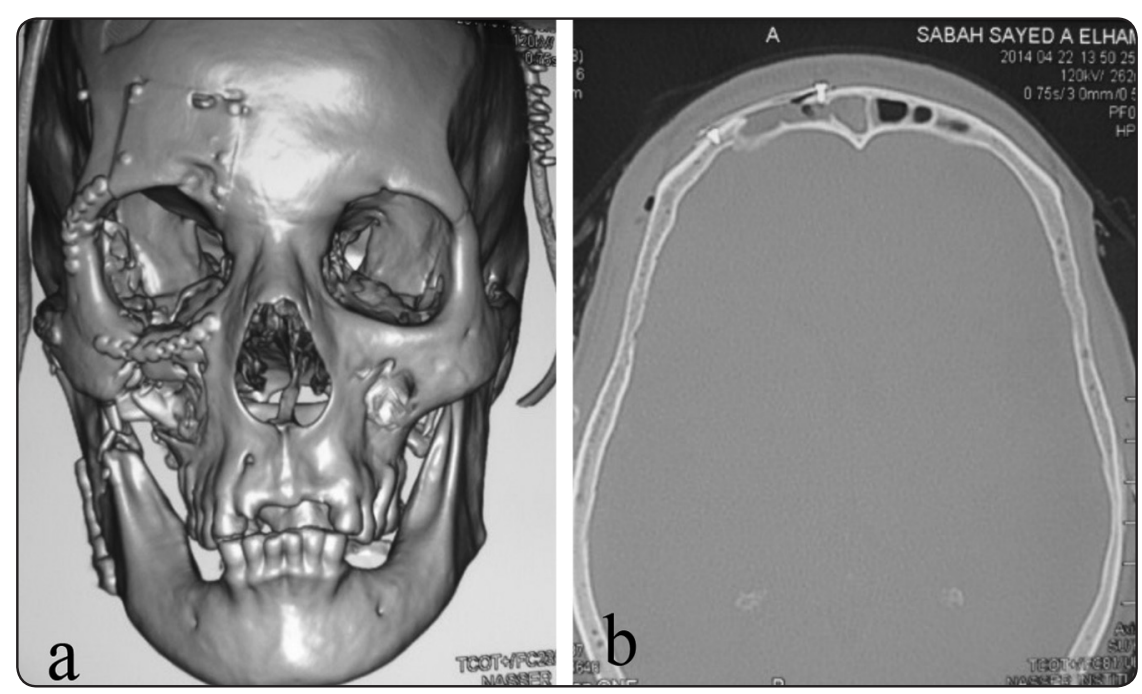

Fig. (6a) 3D CT showing titanium mesh reconstruction of the anterior table and reduction and fixation of the right $\mathrm{ZMC}$ with plates and screws.

Fig. (4b) Immediate Postoperative Axial CT, showing reduced anterior table and fat in place. 


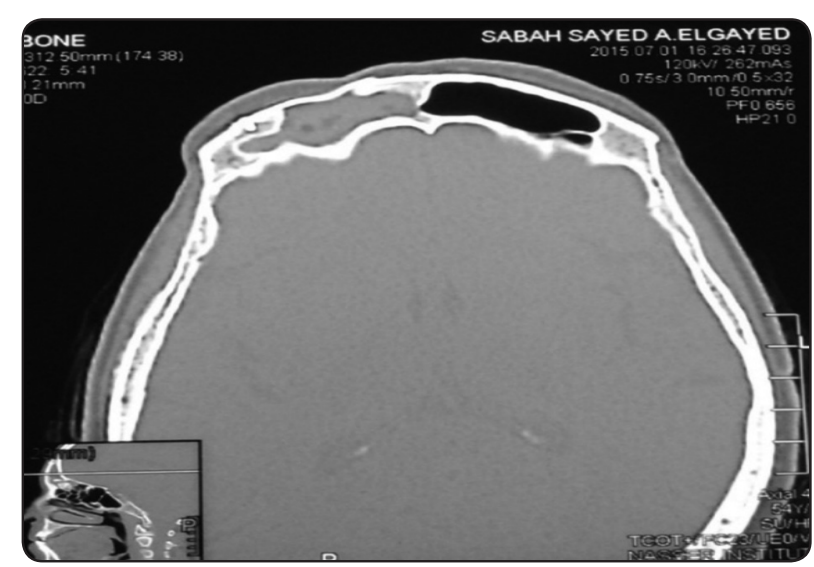

Fig. (7) One year postoperative axial CT showing no evidence of complications, bone occupying lesions or infection and good aeration of the non-operated sinus.

\section{DISCUSSION}

In most cases of facial trauma, appropriate and timely management is crucial to reducing morbidity. However, there is considerable debate and controversy in the literature regarding what constitutes the "appropriate" management of frontal sinus trauma. Treatment principles that have been recommended are aiming at: 1 . Isolation of the neurocranium and cessation of any CSF leak. 2. Prevention of early and avoidance of delayed postoperative complications from the central nervous system. 3 . Restoration of the preoperative facial aesthetics ${ }^{(\mathbf{1 7})}$.

Historically, diagnosis relied heavily on physical examination in combination with plain films, which were notoriously unreliable in predicting the extent of frontal bone or intracranial injury. Many of the early and most influential authors made treatment recommendations based on pre-CT scan imaging, relied heavily on physical examination alone, and most likely operated on patients more often than was absolutely necessary. Today, CT scan images can provide a detailed, 3-dimensional image by which the clinician can assess the need for and extent of operative intervention. The cornerstone of patient evaluation is a thorough physical examination, but it is now generally accepted that all patients with clinical findings suspicious for frontal sinus injury should undergo CT evaluation ${ }^{(18)}$.
Computed tomography (CT) imaging was used in evaluating the fractures in our study. Multiple factors play a role in the choice between surgical or nonsurgical treatment of frontal sinus fractures and subsequently may influence the risk of complications. These factors include fracture type, presence of comminution, cerebrospinal fluid leakage, extent of posterior table involvement, neurological status of the patient, preference of the treating physician and the nasofrontal outflow tract (NFOT) injury. CT has long been an indispensable tool in evaluating several of these factors. With regards to the NFOT, diagnostic criteria have been recently described in an attempt to identify specific findings on $\mathrm{CT}$ imaging that carry a high suspicion for injury and/or obstruction of the NFOT. These criteria include fracture of the frontal sinus floor, fracture of the medial aspect of the anterior table (anterior ethmoid cells), and frank bony outflow tract obstruction. These criteria were relied upon in our study to diagnose the NFOT injury $(5,6)$.

Fracture repair depends on complete identification of the fractured components. Exposure is best achieved by using a standard coronal incision. Exposure via existing lacerations should be reserved for only the smallest fractures of the anterior wall, but this approach most frequently is inadequate. From the literature, the surgical technique with lower recurrence rate and better aesthetic results seems to be the bicoronal approach. Complications of the above mentioned surgical technique, such as numbness, frontal branch (cranial nerve VII) weakness, dural damage with cerebrospinal fluid leakage, and damage of the orbital contents or intracranial structures, are quite unusual and have seldom been reported ${ }^{(\mathbf{9 , 1 9})}$.

Most authors agree that the key element to successful management frontal sinus fractures is an understanding of the sinus drainage. The posteromedial position of the NFD within the sinus makes it particularly susceptible to injury, being injured in as 
many as one third of patients presenting with frontal sinus trauma. There is clinical and experimental evidence to suggest that obstruction of the nasofrontal duct is a significant predisposing factor in the development of complications such as mucocele or mucopyocele formation and that this risk is life-long. Zonis et al., ${ }^{(26)}$ noted that all 4 cases of untreated fractures with NFD injury developed suppurative sequelae. Hybels, Newman and Shenck et al., demonstrated the role of NFD injury in the etiology of suppurative complications in animal models ${ }^{(20)}$.

When frontal sinus drainage is impaired and mucus is retained, a mucocele may develop and act as an expanding tumor causing erosion of the bony walls of frontal sinus, orbits, and skull base. An anaerobic environment may subsequently develop, causing frontal sinusitis that may lead to osteomyelitis, meningitis, or brain abscess. Therefore, it is recommended that fractures involving the NFDs with sufficient energy so as to cause obstruction should be treated generally in the manner as to create a "safe sinus" by complete sinus membrane removal and obliteration of the sinus cavity ${ }^{(21)}$.

In our study, it was decided that every displaced anterior table fracture (isolated or combined with a non displaced posterior table fracture not requiring cranialization) defined as bony displacement more than or equal to the width of the outer table associated with NFD fracture was an indication for Frontal sinus obliteration. This is in accordance with the conclusion of Heller et al., ${ }^{(21)}$ and May et al. ${ }^{(26)}$

There are many alternative biomaterials available for use in frontal sinus obliteration, including obliteration by spontaneous regeneration, autogenous grafts such as bone, muscle, fat, and alloplasts such as methylmethacrylate hydroxyapatite bone cement, calcium phosphate bone cement, and Glass ionomer. Although advocates for each of these techniques or materials exist, autogenous abdominal fat is the most well-studied and has the longest track record of success ${ }^{(2,22)}$.
The technique of obliteration with freshly removed abdominal fat dates back to Bergara (23) and Tato et al., ${ }^{(24)}$, Goodale and Montgomery ${ }^{(25)}$ established the technique of frontal sinus obliteration with fat obliteration as the standard approach for managing the difficult cases. They noted no instance of infection or recurrence and a lack of osteogenesis on plain x-ray films 5 years after surgery.

Another study by Tato et al., ${ }^{(24)}$ also supported the technique of fat obliteration formerly described. They reported a failure rate of $3 \%$ and stated that, on the basis of a small number of re-operated cases, that adipose tissue survives as such in the sinus and also that an unobliterated sinus cavity completely cleansed of its lining membrane may obliterate spontaneously with fibrous tissue.

Fat obliteration was further validated by the study of Montgomery and Pierce ${ }^{(27)}$ with only one failure among 61 cases. Calcaterra and Strahan again reported complete eradication of disease in all but one patient treated with fat obliteration, with no known instance of recurrence. Only in one patient was reoperation required.Another study by Sessions et al. ${ }^{(29)}$, showed a $3.7 \%$ rate of postoperative infection and no postoperative mucocele.

The most comprehensive series and follow-up was that of Hardy and Montgomery, ${ }^{(30)}$ in which the overall complication rate was 18\%: there were abdominal wound complications in $5.2 \%$, acute postoperative infections with necrosis of the implanted fat in $3 \%$, and recurrent chronic sinusitis in $3 \%$ of patients. There was no report on the occurrence of mucoceles. Of 208 patients with obliteration of the frontal sinus, $4 \%$ of cases had to be revised. In the series, $93 \%$ of the patients had no significant symptoms, $6 \%$ had persistent pain, and $1 \%$ had persistent neuralgia. Our results confirm the high success rate of frontal sinus fat obliteration very comparable to other previous studies ${ }^{(23)}$. 


\section{CONCLUSIONS}

Our treatment results suggest that the frontal sinus obliteration utilizing autogenous abdominal fat is a highly effective method of management of fractures of the anterior table. Short term complications were uncommon in our study; however, the incidence of long-term complications associated with frontal sinus fracture awaits prospective, longitudinal study and the effectiveness of fat obliteration for frontal sinus treatment on the longer term cannot be predicted from our study, further studies are recommended with longer follow-up periods. Moreover, the sample in our study is small and further studies should be considered with a greater sample.

\section{REFERENCES}

1. Manolidis S. Management of frontal sinus trauma. Semin Plast Surg;16:261-271; 2002.

2. Xie C, Mehendale N, Barrett D, Bui CJ, Metzinger SE. 30year retrospective review of frontal sinus fractures: The charity hospital experience. J Craniomaxillofac Trauma $6: 7-15 ; 2000$.

3. Cooter, R.D., David, D. J., McLean, A. J., et al. Helmetinduced skull base fracture in a motorcyclist. Lancet 1:84, 1988.

4. Gonty, A. A., Marciani, R. D., and Adornato, D. C. Management of frontal sinus fractures: A review of 33 cases. J. Oral Maxillofac. Surg. 57: 372, 1999.

5. Rodriguez ED, Stanwix MG, Nam AJ, St Hilaire H, Simmons OP, Christy MR et al.,: Twenty-six-year experience treating frontal sinus fractures: a novel algorithm based on anatomical fracture pattern and failure of conventional techniques. Plast Reconstr Surg 122(6):1850-1866;2008.

6. Stanwix MG, Nam AJ, Manson PN, Mirvis S, Rodriguez ED. Critical computed tomographic diagnostic criteria for frontal sinus fractures. J Oral Maxillofac Surg 68(11):2714-2722; 2010.

7. Haug RH. Management of fractures of the frontal bone and sinus. In: Peterson LJ, Indresano AT, Marciani RD, et al (eds). Principles of Oral and Maxillofacial Surgery. Philadelphia, PA: JB Lippincott: 575; 1992.

8. Haug RH, Adams JM, Conforti PJ, Likavec MJ. Cranial fractures associated with facial fractures: a review of mechanism, type, and severity of injury. J Oral Maxillofac Surg 52(7):729-733; 1994.

9. Bell RB1, Dierks EJ, Brar P, Potter JK, Potter BE.;: Analysis of 158 frontal sinus fractures: Current surgical management and complications. J Cranio Maxillofac Surg 28:133, 2000.

10. Luce EA: Frontal sinus fractures: Guidelines to management. Plast Reconst Surg 80:500, 1987.

11. Rohrich, R. J., and Hollier, L. H. Management of frontal sinus fractures. Clin. Plast. Surg. 19: 219, 1992.

12. Bell RB1, Dierks EJ, Brar P, Potter JK, Potter BE.,: Sinus Preservation in Frontal Sinus Fractures. J Oral Maxillofac Surg 2007.

13. D'Addario M, Haug RH, Talwar RM. Biomaterials for use in frontal sinus obliteration. J Long Term Eff Med Implants 14(6):455-65; 2004.

14. Dornhoffer J, Simmons O: Canal wall reconstruction with mimix hydroxyapatite cement: Results in an animal model and case study. Laryngoscope 113:2123, 2003.

15. Eppley B, Hollier L, Stal S: Hydroxyapatite cranioplasty: 2. Clinical experimental with a new quick-setting material. J Craniofacial Surg 10:209, 2003.

16. Bergara AR, Itoiz AO: Experimental study of the behavior of adipose tissue within the frontal sinus of dog. Argetin Rev Oto-Rhino-Laryngol July-Sept:184, 1951.

17. Ioannides C, Freihofer HP, Friens J. Fractures of the frontal sinus: a rationale of treatment. Br J Plast Surg 46: 208 - 14; 1993.

18. Donald PJ, Bernstein L: Compound frontal sinus injuries with intracranial penetration. Laryngoscope 88:225, 1978.

19. Weber R, Draf W, Constantinidis J, et al. Current aspects of frontal sinus surgery. IV: On therapy of frontal sinus osteoma. HNO 43:482 - 6; 1995.

20. Stanely RB Jr, Becker TS: Injuries of the nasofrontal orifices in frontal sinus fractures. Laryngoscope 97:728, 1987.

21. Heller EM, Jacobs JB, Holliday RA: Evaluation of the frontonasal duct in frontal sinus fractures. Head Neck 11:46, 1989.

22. Wiltfang J, Kessler P: Reconstruction of skull bone defects using the hydroxyapatite cement with calvarial split transplants. J Oral Maxillofacial Surg 62:29, 2004.

23. Bergara R. Osteoplastic operation on the large frontal sinus in chronic suppurative sinusitis: end results. Trans Am Acad Ophthalmol Otolaryngol. 1977; 51:643-647. 
24. Tato JM, Sibbald DW, Bergaglio OE. Surgical treatment of the frontal sinus by external route. Laryngoscope. 1954;64:504-521.

25. Goodale RL, Montgomery WW. Anterior osteoplastic frontal sinus operation: five years experience. Ann Otol 1961;70:860 -3.

26. Zonis RD, Montgomery WW, Goodale RL. Frontal sinus disease: 100 cases treated by osteoplastic operation. Laryngoscope 56:1816-1825; 1966.

27. Montgomery WW, Pierce DL. Anterior osteoplastic fat obliteration for frontal sinus: clinical experience and ani- mal studies. Trans Am Acad Ophthalmol Otolaryngol 67: 46-57; 1963.

28. Calcaterra TC, Strahan RW. Osteoplastic flap technique for disease of the frontal sinus. Surg Gynecol Obstet 132: 505-510; 1971.

29. Sessions RB, Alford R, Stratton C, Ainsworth JZ, Shill O. Current concepts of frontal sinus surgery: an appraisal of the osteoplastic flap-fat obliteration operation. Laryngoscope 82:918-930;1972.

30. Hardy JM, Montgomery WW. Osteoplastic frontal sinusotomy: an analysis of 250 operations. Ann Otol 85: 523-532; 1976. 